\title{
Motivasi Kerja Pegawai Di Kantor Keyahbandaran Utama Makassar
}

\author{
Muh. Nasrullah ${ }^{1)}$ Rudi Salam $^{2 *}$, Dwi Pratiwi, ${ }^{3)}$ Risma Niswaty ${ }^{4)}$ \\ Program Studi Pendidikan Administrasi Perkantoran, Universitas Universitas Negeri Makassar \\ Jl. A. P. Pettarani Kampus UNM Gunungsari Baru, Makassar, Indonesi, 90222, \\ *Email : rudisalam@unm.ac.id
}

\begin{abstract}
\begin{tabular}{|c|c|}
\hline Article Info & ABSTRAK \\
\hline $\begin{array}{c}\text { Received: } \\
\text { 25 September } 2017 \\
\text { Revised: } \\
12 \text { Oktober } 2017 \\
\text { Accepted: } \\
\text { 28 Oktober } 2017\end{array}$ & $\begin{array}{l}\text { Penelitian ini bertujuan untuk mengetahui motivasi kerja pegawai di Kantor } \\
\text { Kesyahbandaran Utama Makassar. Jenis penelitian adalah deskriptif, dengan populasi } \\
\text { seluruh pegawai pada Kantor Kesyahbandaran Utama Makassar yang berjumlah } 265 \\
\text { orang/pegawai. Penentuan sampel sebanyak } 20 \text { persen dengan teknik penarikan sampel } \\
\text { secara Proportionate Stratified Random Sampling, sebanyak } 53 \text { orang. Pengumpulan } \\
\text { data dilakukan melalui teknik observasi, angket, wawancara dan dokumentasi, } \\
\text { sedangkan analisis data dilakukan dengan teknik persentase kemudian diinterpretasikan } \\
\text { secara deskriptif. Hasil penelitian menunjukkan bahwa motivasi kerja pegawai di } \\
\text { Kantor Kesyahbandaran Utama Makassar berada dalam kategori tinggi, dilihat dari } \\
\text { faktor pemeliharaan dan faktor pemuasan dengan sub indikator kebijakan organisasi, } \\
\text { supervisi yang baik, kompensasi yang memadai, lingkungan kerja, kepuasan kerja, } \\
\text { prestasi kerja, dan tanggung jawab. }\end{array}$ \\
\hline
\end{tabular}
\end{abstract}
Kata Kunci: Motivasi kerja, Pegawai

\section{Work motivation of employee at harbourmaster office makasar}

\begin{abstract}
This study aims to determine the motivation of employees at the Office Kesyahbandaran Utama Makassar. The type of research is descriptive, with population of all employees at Kesyahbandaran Utama Makassar Office amounting to 265 people / employees. Determination of samples as much as 20 percent with the technique of sampling by Proportionate Stratified Random Sampling, as many as 53 people. Data collection was done through observation technique, questionnaire, interview and documentation, while data analysis was done by percentage technique then interpreted descriptively. The result of the research shows that employee work motivation at Kesyahbandaran Utama Makassar Office is in high category, seen from maintenance factor and satisfaction factor with sub indicator of organization policy, good supervision, adequate compensation, work environment, job satisfaction, job performance, and responsibility.
\end{abstract}

Keywords: work motivation, Employee

How to cite:

Muh. Nasrullah, M., Salam, R., Pratiwi, D., dan, Niswaty, R. (2017). Motivasi Kerja Pegawai Di Kantor Keyahbandaran Utama Makassar. Jurnal Ilmiah Manajemen \& Bisnis, 18(2), 206-211. 


\section{PENDAHULUAN}

Sumber daya yang berkualitas dalam hal ini adalah pegawai merupakan sumber yang sangat menentukan keberhasilan suatu perusahaan. Kedudukan dan peranan pegawai merupakan unsur penggerak proses penyelenggaraan seluruh program kegiatan dalam rangka pencapaian tujuan yang ingin dicapai dalam suatu organisasi pada khususnya, dan tujuan pembangunan nasional pada umumnya. Salah satu tujuan pembangunan nasional yaitu usaha peningkatan kualitas manusia dengan memanfaatkan kamajuan ilmu pengetahuan dan teknologi serta memperhatikan tantangan perkembangan global dewasa ini (Tilaar, 1998; Ali, 2009).

Kedudukan dan peranan Pegawai Negeri Sipil (PNS) sebagai unsur aparatur Negara yang bertugas sebagai abdi masyarakat haruslah menyelenggarakan pelayanan secara adil kepada masyarakat dengan dilandasi kesetiaan dan ketaatan kepada Pancasila dan Undang-Undang Dasar 1945. Peranan pegawai sangat penting dalam pencapaian tujuan organisasi (Tampubolon, 2007; Brahmasari dan Suprayetno, 2009; Murty dan Hudiwinarsih, 2012). Untuk menggerakkan pegawai agar sesuai dengan yang dikehendaki organisasi, maka haruslah dipahami motivasi pegawai yang bekerja di dalam organisasi tersebut, karena motivasi inilah yang menentukan perilaku orang-orang untuk bekerja atau dengan kata lain perilaku merupakan cerminan yang paling sederhana dari motivasi.

Motivasi adalah suatu faktor yang mendorong seseorang untuk melakukan suatu aktivitas tertentu, oleh karena itu motivasi sering kali diartikan pula sebagai faktor pendorong perilaku seseorang (Prasetyo dan Wahyuddin, 2003). Setiap aktivitas yang dilakukan oleh seseorang pasti memiliki suatu faktor yang mendorong aktivitas tersebut. Oleh karena itu, faktor pendorong dari seseorang untuk melakukan suatu aktivitas tertentu pada umumnya adalah kebutuhan serta keinginan orang tersebut. Seperti yang telah ditulis dalam berbagai literatur atau buku-buku mengenai kepegawaian seperti: (Hariandja, 2002; Hakim, 2005; Mappeasse, 2009), dapat diketahui bahwa pegawai mempunyai latar belakang sosial yang berbeda-beda serta tujuan yang berbeda pula, dengan sendirinya faktor tersebut sangat mempengaruhi motivasi seseorang dalam bekerja. Begitu pula halnya dengan adanya berbagai macam kebutuhan menyangkut hidupnya yang akan direalisasikan sehingga mendorong mereka untuk bekerja. Dengan kata lain faktor pemenuhan kebutuhan pegawai harus mendapat perhatian yang serius. Hal ini menjadi penting karena pencapaian tujuan organisasi sangat tergantung pada manusia dalam organisasi yang bersangkutan. Dengan demikian menjadi wajar jika para pegawai mendapat perhatian dari organisasi.

Pegawai dalam suatu organisasi merupakan unsur penting sehingga organisasi dapat benar-benar melaksanakan tugas yang dibebankan kepadanya secara efektif dan efisien (Murty dan Hudiwinarsih, 2012; Batinggi dan Ahmad, 2014). Oleh karena itu, untuk membuat pegawai termotivasi dalam melaksanakan tugasnya diperlukan adanya faktor-faktor yang dapat mendorong munculnya motivasi (dorongan) kerja. Pemberian motivasi kerja pegawai biasanya bertujuan mendorong gairah dan semangat kerja pegawai, meningkatkan produktivitas pegawai, meningkatkan kedisiplinan dan menurunkan tingkat absensi pegawai, dan menciptakan suasana dan hubungan kerja yang baik, mempertinggi rasa tanggung jawab pegawai terhadap tugas-tugasnya. Karena itu kondisi fisik kerja harus terus menerus diperbaiki dengan faktor motivasi sehingga produktivitas dapat terus ditingkatkan.

Berdasarkan pengamatan yang duilakukan Peneliti di kantor Kesyahbandaran Utama Makassar terlihat 
masih ada beberapa pegawai yang motivasi kerjanya rendah, hal tersebut dikarenakan kantor Kesyahbandaran Utama Makassar baru menerapkan pelayanan sistem online pada Penerbitan Buku Pelaut, Perpanjangan Buku Pelaut, Legalisir Buku Pelaut, Keterangan Masa Berlayar, Pemeriksaan Awak Kapal (Crew List), Pengesahan Perjanjian Kerja Laut dan Penyijilan, Dokumen Pengawakan (Safe Manning Document), Sertifikat Kecakapan Pelaut untuk KLM/Tradisional. Sehingga motivasi para pegawai menurun. Tentunya dengan peralihan sistem dari manual ke sistem online sejatinya memudahkan para pegawai dalam bekerja, tetapi hal tersebut memberi dampak kejenuhan pegawai sehingga motivasi kinerja pegawai menurun. Kurangnya pengawasan langsung dari pimpinan terhadap pegawai mengakibatkan para pegawai merasa kurang diawasi kinerjanya. Mereka seakan malas bekerja di kantor atau malas berkantor. Dan tidak hanya itu, apabila pimpinannya tidak ada sebagian pegawai menunda-nunda pekerjaannya, pada waktu istirahat sering kali terlambat masuk, dan masih adanya sebagian pegawai yang meninggalkan ruangan pada jam kerja.

\section{METODE}

Penelitian ini tergolong jenis penelitian deskriptif yang dirancang untuk menggambarkan secara cermat, jelas dan obyektif mengenai motivasi kerja pegawai. Untuk menghindari kemungkinan terjadinya perbedaan persepsi terhadap masalah yang dikaji, dan untuk memudahkan penulis dalam pengumpulan data, maka dipandang perlu memberikan penegasan tentang definisi operasional variabel yang merupakan batasan-batasan terhadap lingkup variabel sebagai indikator penting dalam menentukan keberhasilan penelitian. Untuk mengukur variabel, maka digunakan kuesioner dengan mengajukan sejumlah pertanyaan kepada responden dengan berpedoman pada indikator yang telah ditetapkan (Hamdi dan Bahruddin, 2015).

Dalam penelitian ini yang menjadi populasi penelitian adalah seluruh pegawai di kantor Kesyahbandaran Utama Makassar yang jumlahnya 265 orang. Adapun jumlah sampel yang diambil sebanyak 53 responden. Untuk memperoleh data yang dibutuhkan dalam penelitian ini, maka digunakan teknik observasi, angket, wawancara, dan dokumentasi. Teknik analisis data yang digunakan yaitu secara deskriptif dengan cara mempersentasikan setiap item yang terdapat pada angket pertanyaan. Dalam rangka menganalisis permasalahan yang dikaji maka digunakan rumus yang dikemukakan (Muhson, 2006) sebagai berikut: $\%=\mathrm{n} / \mathrm{n} \times 100 \%$, dimana $\%$ (presentasi), $\mathrm{n}$ (nilai yang diperoleh), dan $\mathrm{N}$ (jumlah seluruh nilai).

\section{HASIL DAN PEMBAHASAN Hasil}

Hasil penelitian menunjukkan bahwa Motivasi Kerja Pegawai di Kantor Kesyahbandaran Utama Makassar berada pada ketegori tinggi. Tingginya motivasi kerja pegawai didukung oleh dua faktor yaitu faktor pemeliharaan dan faktor pemuasan. Hasil analisis data tentang motivasi kerja pegawai di atas, maka dapat disimpulkan bahwa Motivasi Kerja Pegawai di Kantor Kesyahbandaran Utama Makassar berada dalam kategori tinggi dengan nilai yang diperoleh sebanyak 4161 serta nilai idealnya sebanyak 4664 dan dipersentasekan menjadi 89,2 persen dapat dilihat pada tabel 1. 
Tabel 1. Motivasi Kerja Pegawai di Kantor Kesyahbandaran Utama Makassar

\begin{tabular}{lllllll}
\hline No & Indikator & $\begin{array}{l}\text { Nilai } \\
\text { diperoleh }(\mathbf{n})\end{array}$ & $\begin{array}{l}\text { Nilai } \\
(\mathbf{N})\end{array}$ & Ideal & $\%$ & Kategori \\
\hline 1 & Kebijakan Organisai & 744 & 848 & 87,7 & Tinggi \\
2 & Supervisi yang Baik & 388 & 424 & 91,5 & Tinggi \\
3 & Kompensasi & 529 & 636 & 83,2 & Tinggi \\
4 & Lingkungan Kerja & 757 & 848 & 89,3 & Tinggi \\
5 & Kepuasan Kerja & 769 & 848 & 90,7 & Tinggi \\
6 & Prestasi Kerja & 380 & 424 & 89,6 & Tinggi \\
7 & Tanggung Jawab & 584 & 636 & 91,8 & Tinggi \\
\hline & Total & $\mathbf{4 1 6 1}$ & $\mathbf{4 6 6 4}$ & $\mathbf{8 9 , 2}$ & Tinggi \\
\hline
\end{tabular}

Sumber : olah data penelitian (2017)

\section{Pembahasan}

Kebijakan organisasi pada Kantor Kesyahbandaran Utama Makassar berada pada kategori tinggi. Hal ini menunjukkan bahwa kebijakan yang dikeluarkan pimpinan tidak terlepas dari tugas pokok pegawai, dalam pemutasian pun pimpinan berusaha sedapat mungkin agar pegawai yang dimutasi sesuai dengan keterampilannya, dan pimpinan selalu memperhatikan promosi bagi pegawai yang berprestasi. Sebagai pimpinan dalam mengambil suatu kebijakan itu tidak lain adalah untuk kepentingan bersama, sehingga segala tugas pokok yang dilakukan oleh masing-masing pegawai dapat dikerjakan dengan baik dan efisien (Drucker, 1995; Dewi, 2012; Zehnder, et al., 2017).

Supervisi yang baik pada Kantor Kesyahbandaran Utama Makassar berada pada kategori tinggi. Dimana atasan selalu memberikan pengarahan/bimbingan kepada pegawai setiap tugas yang diberikan, tujuan agar perintah yang diberikan dapat diselesaikan sesuai dengan yang diinginkan, dan pimpinan juga selalu melakukan pengawasan terhadap pekerjaan pegawainya baik secara langsung maupun tidak langsung. Pekerjaan adalah memberikan pengarahan, bimbingan kerja pada karyawan agar dapat melaksanakan kerja dengan baik tanpa membuat kesalahan (Wachid dan Majid, 2016; Adelino, et al., 2017).
Kompensasi pada Kantor Kesyahbandaran Utama Makassar berada pada kategori tinggi. Hal ini terlihat dari, bahwa pimpinan memperhatikan pemberianpemberian insentif kepada pegawainya, dalam pemberian insentif ini berdasarkan target yang dicapai pegawai, adanya tunjangan hari raya yang diberikan kepada pegawai yang ada pada kantor tersebut, serta tersedianya asuransi kesehatan adalah salah satu penggerak motivasi pegawai dalam bekerja, juga senada dengan pendapat beberapa peneliti seperti Franklin, et al., (2015); Muayanah, et al., (2017); Rozzaid, et el., al., (2016); Young et al. (2016) yang menyatakan bahwa Kompensasi adalah segala sesuatu yang diterima oleh pekerja sebagai balas jasa atau kerja.

Lingkungan kerja pada Kantor Kesyahbandaran Utama Makassar berada pada kategori tinggi. Hal ini terlihat dari suasana kerja yang nyaman dan kompak, fasilitas yang memadai, lingkungan kerja yang kondusif serta kerja sama yang baik karena adanya perhatian dari atasan kepada bawahan. Sedangkan kepuasan kerja pada Kantor Kesyahbandaran Utama Makassar berada pada kategori tinggi. Dimana pegawai dapat menyelesaikan tugasnya sesuai dengan perintah atasan, pimpinan yang selalu memberikan kesempatan kepada pegawai dalam mengikuti pelatihan dan pendidikan sehingga pegawai selalu berusaha belajar untuk mengembangkan 


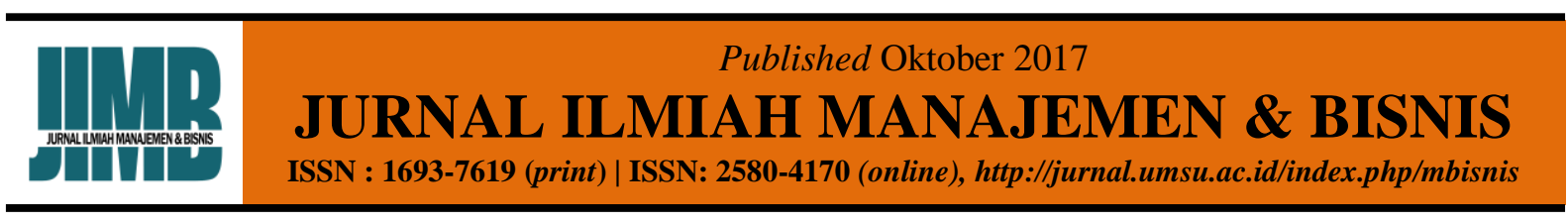

kinerjanya, serta pujian yang sering didapatkan pegawai dari atasan terhadap kerja yang dilakukannya. Oleh karena itu berdampak pada prestasi kerjad dan tanggung jawab pegawai pada kategori tinggi. Hal ini terlihat dari kemampuan dan tanggung jawab pegawai dalam melaksanakan pekerjaan mereka dan kepercayaan yang diberikan atasan kepada pegawai dalam melaksanakan pekerjaan (Budiningsih, et al., 2017; England, 2017; Rahmawati, 2017).

\section{SIMPULAN}

Berdasarkan hasil analisis data dan pembahasan maka hasil penelitian ini dapat disimpulkan bahwa tingkat Motivasi Kerja Pegawai di Kantor Kesyahbandaran Utama Makassar berada dalam kategori tinggi, dilihat dari faktor pemeliharaan dan pemuasan dengan sub indikator kebijakan organisasi, supervisi yang baik, kompensasi yang memadai, lingkungan kerja, kepuasan kerja, prestasi kerja dan tanggung jawab.

\section{REFERENSI}

Adelino, M., Ma, S. dan Robinson, D. (2017). Firm age, investment opportunities, and job creation, The Journal of Finance. Wiley Online Library.

Ali, M. (2009) Pendidikan untuk pembangunan nasional: menuju bangsa Indonesia yang mandiri dan berdaya saing tinggi. Jakarta: Intima.

Batinggi, A. dan Ahmad, B. (2014). Manajemen Pelayanan Umum. Jakarta: Universitas Terbuka.

Brahmasari, I. A. dan Suprayetno, A. (2009). Pengaruh Motivasi Kerja, Kepemimpinan dan Budaya Organisasi Terhadap Kepuasan Kerja Karyawan serta Dampaknya pada Kinerja Perusahaan (Studi kasus pada PT. Pei Hai International Wiratama Indonesia), Jurnal Manajemen dan Kewirausahaan, 10(2), 124.
Budiningsih, S., Warso, M. M. dan Yulianeu, Y. (2017). Hubungan Pengembangan Karir dan Kompensasi Terhadap Kepuasan Kerja dan Implikasinya Pada Komitmen Organisasional PT. Pertani (Persero), Wilayah Jateng \& DIY," Journal of Management, 3(3).

Dewi, S. P. (2012). Pengaruh pengendalian internal dan gaya kepemimpinan terhadap kinerja karyawan SPBU Yogyakarta (studi kasus pada spbu anak cabang perusahaan RB. Group)," Nominal: Barometer Riset Akuntansi dan Manajemen, 1(1).

Drucker, P. F. (1995). People and performance: The best of Peter Drucker on management. Routledge.

England, P. (2017). Households, employment, and gender: A social, economic, and demographic view. Routledge.

Franklin, G. M. et al. (2015). Workers' compensation: poor quality health care and the growing disability problem in the United States. American journal of industrial medicine. Wiley Online Library, 58(3), 245-251.

Hakim, T. (2005) Belajar secara efektif. Jakarta: Swadaya Nusantara.

Hamdi, A. S. dan Bahruddin, E. (2015) Metode penelitian kuantitatif aplikasi dalam pendidikan. Bogor: Deepublish.

Hariandja, M. T. E. (2002) Manajemen sumber daya manusia. Jakarta: Grasindo.

Mappeasse, M. Y. (2009) "Pengaruh Cara dan Motivasi Belajar Terhadap Hasil Belajar Programmable Logic Controller (PLC) Siswa Kelas III Jurusan Listrik SMK Negeri 5 Makassar," Jurnal Medtek, 1(2), 1-6.

Muayanah, S., Haryono, A. T. dan Wulan, H. S. (2017) Pengaruh Kompensasi, Lingkungan Kerja, dan Komitmen Organisasi Terhadap Organizational Citizenship Behavior dengan 
Kepuasan Kerja sebagai Variabel Intervening (Studi kasus pada karyawan PT. Fajar Lestari Sejati semarang). Journal of Management, $3(3)$.

Muhson, A. (2006) Teknik Analisis Kuantitatif. Yogyakarta: Universitas Negeri Yogyakarta.

Murty, W. A. dan Hudiwinarsih, G. (2012). Pengaruh kompensasi, motivasi dan komitmen organisasional terhadap kinerja karyawan bagian akuntansi (studi kasus pada perusahaan manufaktur di Surabaya). The Indonesian Accounting Review, 2(2), 215-228.

Prasetyo, E. dan Wahyuddin, M. (2003). Pengaruh kepuasan dan motivasi kerja terhadap produktivitas kerja karyawan Riyadi Palace Hotel di Surakarta," Retrieved April, 2, hal. 2016.

Rahmawati, L. (2017). Kualitas Pelayanan dan Pengaruhnya Terhadap Tingkat Kepuasan Nasabah di BMT UGT Sidogiri Capem Waru. eL-Qist: Journal of Islamic Economic and Business (JIEB), 3(1).

Rozzaid, Y., Herlambang, T. dan Devi, A. M. (2016). Pengaruh Kompensasi dan Motivasi Terhadap Kepuasan Kerja Karyawan," Jurnal Manajemen Dan Bisnis Indonesia, 1(2).

Tampubolon, B. D. (2007). Analisis faktor gaya kepemimpinan dan faktor etos kerja terhadap kinerja pegawai pada organisasi yang telah menerapkan SNI 19-9001-2001. Jurnal standardisasi, 9(3), hal. 106-115.

Tilaar, H. A. R. (1998). Beberapa agenda reformasi pendidikan nasional dalam perspektif abad 21. Magelang: IndonesiaTera.

Wachid, N. dan Majid, A. (2016). Pengaruh Pengalaman Praktik Kerja Industri dan Kompetensi TIK terhadap Kesiapan
Kerja Kelas XII SMKN 3 Yogyakarta Tahun Ajaran 2012/2013. UNY.

Young, A. E. et al. (2016). Workplace outcomes in work-disability prevention research: a review with recommendations for future research. Journal of occupational rehabilitation. Springer, 26(4), 434447.

Zehnder, C., Herz, H. dan Bonardi, J.-P. (2017). A productive clash of cultures: Injecting economics into leadership research," The Leadership Quarterly. Elsevier, 28(1), 65-85. 